\title{
The impact of long-term loading and changes in moisture content and relative humidity on timber purlins and beams
}

\author{
Received (in revised form): 16th June, 2005
}

\begin{abstract}
Alan Holmes
is a chartered building surveyor and the Managing Director of building surveyors and asset managers, Elliott Holmes Johnson Ltd. He has specialised in building defects of residential properties for 14 years. Elliott Holmes Johnson is a firm of independent consultants who advise residential social landlords on asset management strategies as well as carrying out single surveys for home purchasers.
\end{abstract}

\begin{abstract}
A common problem found in surveys of domestic residential properties - in particular for clients with large housing stocks such as local authorities - is deflection in timber purlins and beams. Timber's performance changes with long-term loading and variations in humidity and moisture. Changing the building environment can have a dramatic effect on timber components, but sometimes things are not as straightforward as first thought. This paper considers how the environment of a building can affect the performance of timber members.
\end{abstract}

\section{Keywords:}

timber, purlin, bressummer, ventilation, humidity, cupping, twisting, bowing, creep deflection

\section{INTRODUCTION}

A local authority tenant reported cracking in the timber purlin of their home's roof. The local council asked the author's company to report on the adequacy of the roof structure. What seemed to be a simple deflection of the purlin ended up questioning the changing environment in the roof space and the effect it had had on timber members. This paper looks at the effects that loading and changes in moisture content and relative humidity can have on timber in buildings.

\section{LONG-TERM LOADING OF BEAMS}

A typical example of deterioration in timber affecting its strength is the bressummer beam. This is probably the most common cause of failure with timber lintels. When a beam of whatever material is loaded an initial deflection occurs and with steel or concrete that is the end of the matter. Timber under prolonged high stress, however, will very gradually continue to deflect with the passing of years, a phenomenon known as creep deflection. The structural member most at risk is the beam, or bressummer, supporting the external wall and first floor over a 


\section{Bressummer beam deflection}

\section{Risk from fungal decay}

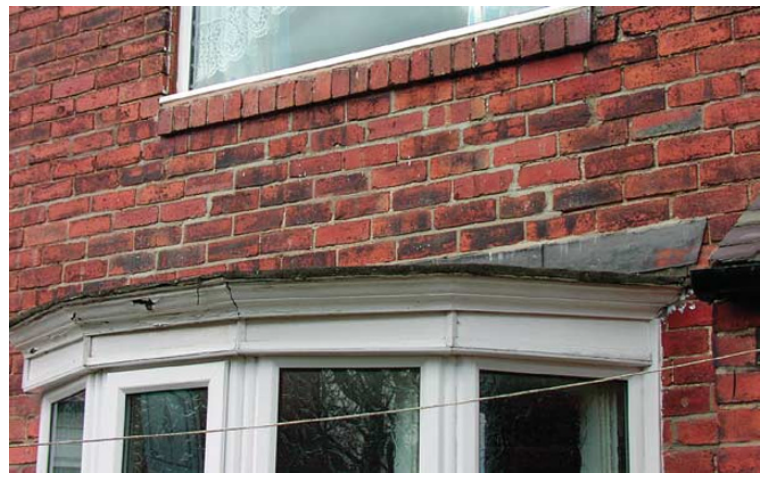

Figure 1: Stepped cracking above a bay window

single-storey bay window and often a whole street of similar houses will exhibit the same pattern of stepped cracking above their bay windows (see Figure 1).

The beam or bressummer is normally made up of three floor joists with spacers between to make up the wall thickness, while the floor joists either go over the top and form the ceiling/roof of the bay or, more commonly, are tusk tenoned into the inside joist.

If the cracks are just caused by nothing more sinister than creep deflection and provided the bressummer is adequate in other respects then normally all that is needed is to rake out the cracked joints and repoint.

\section{WATER INGRESS AND THE RISK OF FUNGAL DECAY}

If the property was built earlier than about 1920 and the bay has a flat roof it would almost certainly have been leaded originally. Sheet lead has a life of about 50 years after which deterioration occurs either by splitting due to thermal stress or the formation of pin holes caused by corrosion or breakdown of small foreign particles in the original lead. This leads to water penetration which, if neglected, could lead to wet or dry rot in the bay roof timbers or the bressummer. If the lead has been replaced with felt this is usually a sign that there has been water penetration in the past and it should be treated with suspicion.

Unfortunately, it is not easy to check whether the bressummer has been affected by rot without extensive opening up unless there are obvious signs of, say, a dry rot fungus. The properties most at risk are houses built prior to 1920 , with a flat roof over a bay that has had the original lead replaced. If in these circumstances the cracks are relatively recent and show on the inside as well as the outside of the wall it can be assumed that there is probably wet or more likely dry rot in the bressummer, in which case it must be removed and replaced with a steel beam.

\section{TIMBER SHRINKAGE}

A common problem in properties is the shrinkage of timber shortly after construction with opening of joints in architraves and skirting, and twisting and warping of timber doors. Another significant effect is shrinkage of timber following a flood. Figure 2 shows splitting in a 
Rapid drying following flood

\section{Relative humidity}

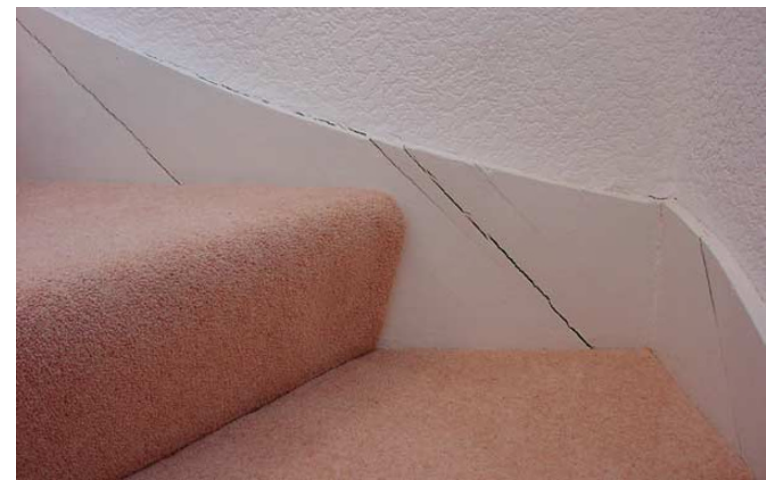

Figure 2: Splitting in the timber string of a staircase

staircase string painted after a property had suffered a severe flood following a burst water tank in the roof.

The client in this case believed that the property had fully dried and carried out repairs and redecoration, six months later cracks in the timber string of the staircase and opening joints in door architraves and skirting appeared and the author's company was called to inspect structural movement. There was no structural movement, moisture contents in the timber were found to be 19 per cent when tested with an electronic resistance moisture meter and the timber was continuing to dry out.

\section{CHANGING HUMIDITY LEVELS}

The main case study started when a client's tenant reported significant cracking in the timber structure of their home. The splitting in timber had been diagnosed as structural movement due to loads from the roof. The author's company was asked by the local authority to inspect the cracking and structural movement, report on the cause and recommend repairs. This was a very interesting case where changes to ventilation in a roof void had affected the relative humidity and led to volumetric changes in the timber members of the roof structure. The house was a typical local authority, semi-detached house with brick cavity walls supporting a twin pitched and hip-end roof.

The original roof covering was asbestos cement tiles, the roof had been recovered with 'Eternit' type slate substitute tiles. The roof had vent tiles in the external face above eaves level to provide cross ventilation (see Figure 3); however, an internal inspection revealed that the vent tiles did not extend beyond the sarking felt and therefore they were not ventilating the roof space. There was no ridge ventilation.

The tiles were laid over plastic 'monarflex' type sarking felt, which is impermeable and will not allow vapour evaporation. There was no evidence of condensation or water penetration in the roof void at the time of the inspection. The ventilation met the requirements of The Building Regulations 1991 as amended, Approved Document F2, The Building Standards (Scotland) Regulations 1990-1994 Part G where appropriate and British Standard (BS) 5250. 


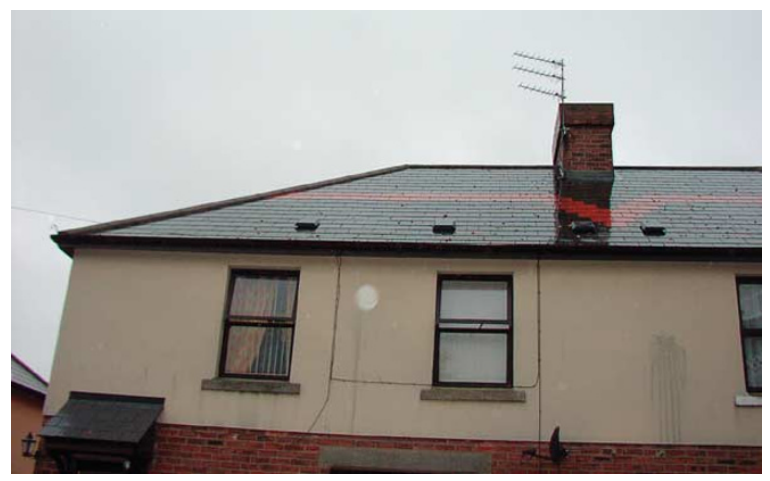

Figure 3: The replacement roof with vent tiles

\section{Ventilation to the roof}

The ventilation roof tiles provided a $20,000 \mathrm{~mm}^{2}$ free area of ventilation. BS 5250, the Code of Practice for the Control of Condensation in Buildings and the Building Regulations Approved Document F2 have recommended for many years that the way to control the build-up of condensation in roofs is through the use of ventilation. While systems that avoid the use of ventilation have been marketed by some companies, ventilation is still the most popular system for complying with the

\section{Roof void ventilation} Building Regulations Approved Document F2.

The basic requirements for ventilating a traditional cold loft space are that air should enter the loft at the lowest point on one side of the roof and exit on the opposite side of the roof. Water vapour rises up through quilt or fibrous insulation and meets the air in the loft, where some of the moisture is absorbed - the quantity depends on the air temperature.

Warm air can absorb more water vapour than cold air. If the air layer directly above the insulation is constantly changing it stands a good chance of absorbing most or all of the water vapour and taking it outside. The warmer the air in the rooms below the insulation the greater the amount of moisture that can be absorbed. The cooler the loft the less moisture that can be held before condensation forms. Consequently, if air leakage into the loft is full of moisture then the risk of condensation forming in the loft increases. This can be reduced if a vapour check layer is introduced below the insulation, such as foil-backed plasterboard or a layer of polythene, along with sealed holes and openings.

Over time it is almost impossible to keep out all water vapour from the loft. During cold weather the risk of condensation forming is greater. Air flow through the loft can discourage condensation. On most days there is a slight breeze causing a small positive wind pressure on one side of a roof and a small negative pressure on the opposite side. This pressure difference can drive a flow of air through the loft provided there are suitable air gaps on each side of the roof linked to the loft space. But if there is no wind, then there will be no positive or negative pressure to drive the air through the loft. Therefore, air that leaks through the insulation will be warmer than the air in the loft and will try and rise to the top of the roof. It will become trapped under the ridge and start to cool, 


\section{The case study}

\section{The subject property}

where it will form condensation on cold surfaces. If there was a vent at the ridge, the air would be carried outside and cease to be a problem.

Air should never be allowed to enter at a ridge, only leave. It is for this reason that most roof tile manufacturers recommend eaves to ridge ventilation as it will cope with both the wind and no wind situations. (Eaves to eaves ventilation is designed to work with a slight breeze.)

The size of the grills through which air enters and leaves a roof is prescribed as a continuous $10 \mathrm{~mm}$ gap at eaves or low level, with a continuous $5 \mathrm{~mm}$ gap at ridge or high level. These figures are a compromise. On calm days they are too small, on very windy days they are too large. Temperature and moisture levels constantly change, making a precise level of ventilation almost impossible to achieve, but over time more water vapour should leave the loft than enters it from below.

Returning to the case study it was noted that, following the roof recovering:

- Ventilation tiles did not penetrate the sarking and therefore did not ventilate the roof void.

- There were a few very large vent tiles or grills rather than a continuous slot or grill. The larger the vent or grill, the greater the distance between the vents or grills resulting in a massive localised air flow close to the vent and little or no air flow as one moved away from the vents.

- Vents were directly in line with vents on the opposite side. This could create a wind tunnel across the roof between the large vents and no air movement as little as $600 \mathrm{~mm}$ away.

Marley roofing guidelines (available at: www.marleyroofing.co.uk) state that the worst combination is four large vent tiles positioned at mid-span on each face of a pyramid roof in an exposed location. This is similar to the situation at the house inspected, except the tile vents did not penetrate the sarking (Table 1).

\section{ROOF STRUCTURE}

The roof structure itself comprised $50 \mathrm{~mm} \times 75 \mathrm{~mm}$ common rafters at $425 \mathrm{~mm}$ centres supported on a single $65 \mathrm{~mm} \times 200 \mathrm{~mm}$ purlin to each roof slope and the hip rafters. The purlins were supported by a single truss, with a tie beam and collar beam spanning between the front and rear purlins fixed to the common rafters, and a strut notched over the roof

Table I: Performance data

\begin{tabular}{llccr}
\hline $\begin{array}{l}\text { All tile profiles stepped } \\
\text { pipe adaptor (diameter } \mathbf{m m})\end{array}$ & $\begin{array}{l}\text { Free area } \\
\left(\mathrm{mm}^{2}\right)\end{array}$ & $\begin{array}{l}\text { Pressure resistance }(\mathrm{Pa}) \\
\text { (litres/second airflow) }\end{array}$ & \\
\hline & & 15.00 & 30.0 & 60.0 \\
100 & & 0.63 & 2.6 & 10.0 \\
110 & 20,000 & 0.80 & 3.3 & 12.9 \\
125 & & 1.14 & 5.9 & 18.6 \\
150 & & 1.45 & 5.9 & 25.0 \\
160 & & 1.55 & 6.1 & 27.0 \\
\hline
\end{tabular}

Source: www.marleyroofing.co.uk 


\section{Permissible stress design}

\section{Stress grading}

purlin. The strut resisted inward deflection but did not prevent downslope deflection. In addition, there was a half truss spanning between the main truss and the side wall with a tie beam and single strut but no collar beam. An inspection revealed up to $12 \mathrm{~mm}$-wide shakes along the roof purlins on all slopes. There was a broken common rafter on the rear roof slope. From the inspection there was no evidence of distress in the purlins; however, it was unlikely that the purlins could be justified using current engineering codes. Apart from the broken rafter, which probably occurred during re-roofing, no distress in the roof slopes was evident.

\section{STRESS GRADING}

Calculations showed that the roof purlins did not comply with current regulations. Structural design criteria for wood components assume that the wood has adequate strength, but this will depend upon the species and grading of the timber. In BS 5268: Part 2, Code of Practice for Permissible Stress Design, Material and Workmanship, design flexibility is allowed by relating design criteria to strength class, eg SC3, GS or M50 grades. GS represents the general structural grade determined by visual stress grading and M50 is the equivalent grade determined by machine stress grading. The first feature in visual stress grading is to determine that the wood has the correct cross section, ie this has not been altered by sawing or machining. The presence of wane, which is the curved edge of the log along the arris of the wood, also affects the cross section.

Structural timbers (as required for bridges) are stress graded according to the proportion of defects in the sawn section. For softwoods the gradings are divided into GS and SS (special structural grade). Where the grading has been done by machine, the gradings are MGS or MSS. The timber is further defined by species, eg Grade GS Scots pine. Hardwoods have a single grading of HS (hardwood structural). Where the selection of a timber species is not important, timber may be specified by its SC (strength classification). For further details see BS 4978 for softwood and BS 5756 for hardwood.

Softwoods most commonly used for bridges are Douglas fir, larch and Scots pine, either imported or home grown, meeting strength classification SC3, SC4 or higher. Timbers to strength classification SC1 and SC2 are unlikely to be useful for footbridges. Hardwoods used are mostly imported, such as Keruing and Ekki.

As a result of amendments to BS 4978 and BS 5268, there are new 'marks' for structural timber graded from 1st March, 1995. The amendments require all structural softwood specified for dry covered applications (rafters, joists and studwork) having a thickness of less than $100 \mathrm{~mm}$ to have been dried to a moisture content of 20 per cent or less at the time of stress grading. The grading mark must include 'DRY' or 'KD' (kiln dried).

The most important factor in stress grading is the knot area ratio. The ratio of knot area projected on a cross section relative to the total area of the wood determines the integrity of the cross section of timber. Splits, fissures and resin pockets also must be taken into account for grading. Unlimited fissures are permitted if they are less than one-half of the 


\section{Shakes, splits and fissures}

\section{Overloading}

thickness of the piece. If they are greater than half the thickness but less than the whole thickness, their length should not exceed $900 \mathrm{~mm}$ for GS grade or $600 \mathrm{~mm}$ for SS grade, or one-quarter of the length of the piece, whichever is the lesser.

The grading also considers growth rate rings and there should not be less than four rings per $25 \mathrm{~mm}$, the slope of the grain should be less than one in six for GS grades and one in ten for SS grades. Finally, the wood should not be excessively distorted. Within a $3 \mathrm{~m}$ length the bow should not exceed one-half of the thickness, spring should not exceed $15 \mathrm{~mm}$ and twist should not exceed $1 \mathrm{~mm}$ per $25 \mathrm{~mm}$ width. The depth of cupping should not exceed $1 / 25$ th of the width.

\section{SPLITTING IN ROOF MEMBERS}

In the case study, the existing timber with shakes, splits and fissures exceeding $900 \mathrm{~mm}$ in length and extending over half of the thickness of the timber, combined with the slope of the grain, would give it a very poor stress grade (see Figure 4 - please note the tenant had placed the tape measure over the purlin, it is not generally used as a surveying tool, but does emphasise the extent of the cracking).

When an old timber roof is recovered, it can be subjected to substantially higher loads from the new tiles or slates than from the original ones. A roof construction that had performed satisfactorily before recovering may show signs of dishing or sagging of the ridge and may collapse under a heavy snow load. This is particularly relevant when a roof of Welsh slates is replaced with plain clay tiles or concrete interlocking tiles as the self-weights shown in Table 2 demonstrate. It can be seen from Table 2 that the dead load easily can be doubled when changing from, say, Welsh slates to concrete interlocking tiles or clay tiles.

Overloading will normally manifest itself in sagging purlins and sometimes roof spread. In the case study, the existing roof covering had been replaced with a new roof covering of similar weight. The loads on

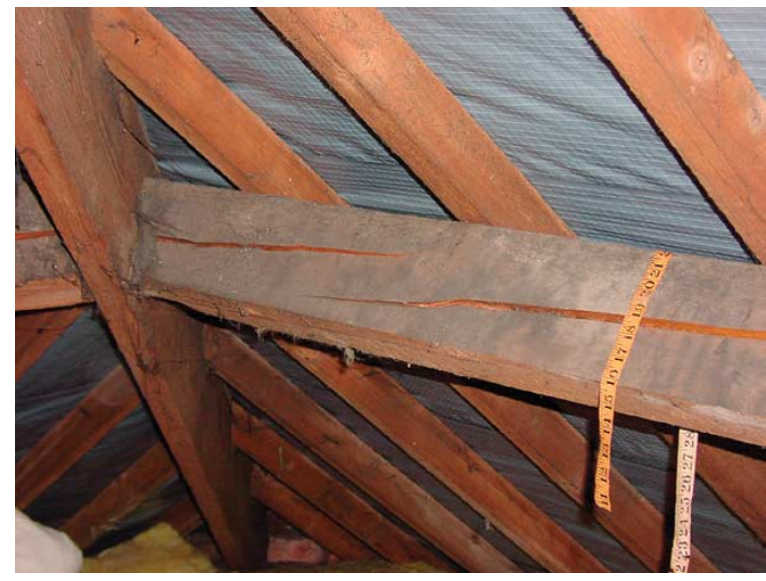

Figure 4: Splitting in roof members 
Table 2: Differing weights for slates and tiles

\begin{tabular}{lll}
\hline & Type & Weight $\left(\mathrm{kg} / \mathrm{m}^{2}\right)$ \\
\hline Slates & Welsh thins & 25 \\
\multirow{2}{*}{ Tiles } & Westmorland thicks & 78 \\
& Clay, plain & $59-71$ \\
& Concrete, interlocking & $48-56$ \\
\hline
\end{tabular}

the purlins had not been increased and the shakes in the purlins were not considered to be caused by deflection or shear stresses.

The properties of wood are profoundly influenced by the presence of water. Freshly felled timber is often described as green and has a very high moisture content varying typically between 60-200 per cent. The loss of bound moisture from the cell space and eventually the cell walls results in shrinkage and progressive change in the physical properties. In addition, the amount of bound water remaining in the wood is approximately proportional to the relative humidity of the surrounding atmosphere; wood is hygroscopic and will gain or lose water with changes in atmospheric humidity, and these changes result in swelling and shrinkage. Swelling or shrinkage with changes in moisture content is known as movement. In the longitudinal direction the movement is generally very low, only about 0.1 per cent for a 12 per cent change in moisture content. In contracts, the movement in the radial direction for the same moisture content is about $3-5$ per cent and in the tangential direction 5-15 per cent.

Warping is the general term for distortions on drying and takes several forms as detailed below.

Warping of timber
- Cupping is warping across the grain or width of the board and arises in flat sawn boards because the outer zones of the trunk, particularly the sap wood, shrink to a greater extent than the inner zones, giving a planoconvex surface on the outer side of the board or timber section relative to the trunk (see Figure 5).

- Twisting arises in timber due to the presence of spiral grain.

- Bowing is longitudinal curvature arising perpendicular to the surface, usually occurring as sagging while wood is stacked during drying or from loading and creep deflection (see Figure 6).

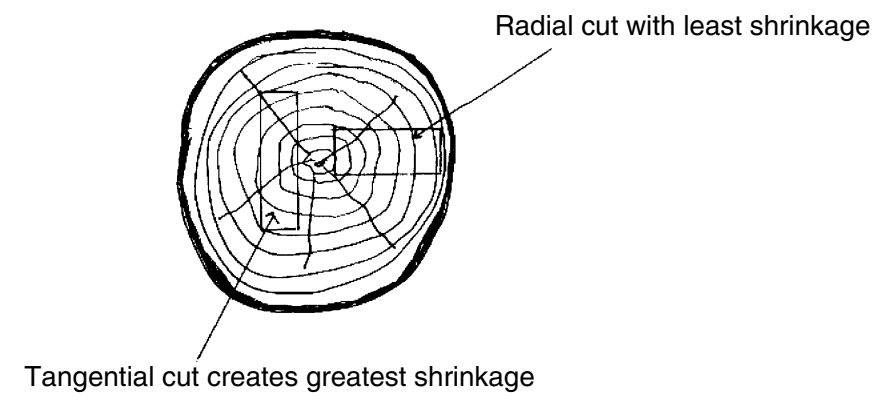

Figure 5: Illustration of cupping in flat sawn wood 


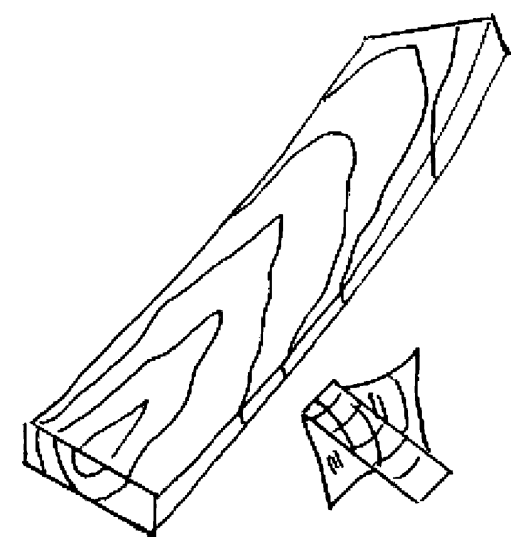

Figure 6: Illustration of bowing

- Spring or crooking is longitudinal curvature within the pane of the board caused by tensions within the original tree (see Figure 7).

In the case study, when the roof was recovered over an impervious sarking the ventilation to the roof was reduced. The ventilation tiles installed were poorly positioned and, as they did not pass the impermeable sarking, were totally ineffective. Insulation over the ceiling was increased and the relative humidity in the roof space was drastically altered. In turn, this affected the hygroscopic timber and caused shrinkage, cupping and splitting.

The timber's stress grading was affected and what was originally a suitable stress grade for the roof purlins was now significantly reduced due to the splitting in the purlin. It was imperative that the relative humidity in the roof void be adjusted by extending the roof tile vents through the sarking to ventilate the roof space and decrease the relative humidity.

\section{Case: conclusion}

The inspection showed that the roof structure was not suffering from any major distress; however, to improve the integrity of the split purlins it was recommended that the upper face be overclad with $12 \mathrm{~mm}$ plywood. In plywood, the grain runs horizontally in both directions within the plane of the board and it is equally strong in both directions. The adhesives in the plywood have been developed to resist very high

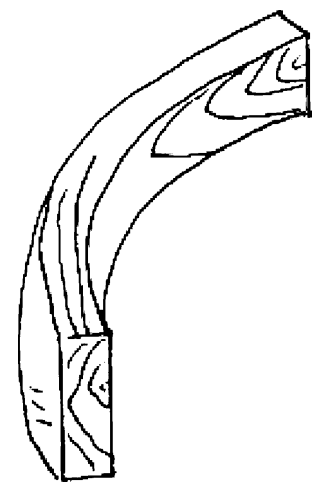

Figure 7: Illustration of spring or crooking 


\section{Case: recommended repairs}

\section{Subsequent moisture variation following stress grading}

stresses. The plywood should be cut, in full lengths, to cover the full face of the purlin and glued and screwed at $150 \mathrm{~mm}$ centres, $15 \mathrm{~mm}$ from both the top and bottom edges of the purlin.

\section{RECOMMENDED REPAIRS}

The author's company specified that $2,400 \mathrm{~mm} \times 12 \mathrm{~mm}$ thick marine plywood sheets should be cut along their length, to cover the full face of the purlin. The plywood was to be glued and screwed to the purlin at $150 \mathrm{~mm}$ centres, $15 \mathrm{~mm}$ from both the top and bottom edges of the purlin. It was recommended that the vent tiles should be extended through the sarking to ventilate the roof space. In addition, an SC4 $50 \mathrm{~mm} \times 75 \mathrm{~mm}$ rafter should be bolted alongside the broken rafter with M12 bolts and toothplate connectors at $600 \mathrm{~mm}$ centres.

\section{CONCLUSION}

This paper was not written to detail a single survey, but rather to help readers to consider that cracks in timber can be wrongly identified and are not always evidence of structural movement due to loading. The ventilation and control of unexposed voids (roof spaces, sub-floor voids etc) are critical and should be correctly specified when recovering roofs. When a timber is stress graded, it is graded on its condition at that time. Subsequent moisture variation, twisting, cupping, fungal decay and insect attack will affect the stress grading. Where a structural timber was in design it may be no longer adequate after use.

\section{References}

BS 5250 (1989) Code of Practice for the Control of Condensation in Buildings, British Standards Institute.

The Building Regulations, (1995). Approved Document F2.

Higgins, R.M. (1990) Recovering Old Timber Roofs, Fact Sheet 2, section 6 'Structural Timbers' and section 13d 'Sagging Lintels'.

Marley roofing guidelines available at www.marleyroofing.co.uk.

Richardson, B.A. (1991) Defects and Deterioration in Buildings, E\&F N Spon, Chapman and Hall, London. 